\title{
The Effect of Teaching Collocations to Kurdish Tertiary Students Through Mobile Learning
}

\author{
https://doi.org/10.3991/ijim.v14i18.16801
}

\author{
Sasi Sekhar Mallampalli ${ }^{(\bowtie)}$, Shriya Goyal \\ Uttaranchal University, Dehradun, India \\ mallampallisasisekhar@gmail.com
}

\begin{abstract}
Proficiency in English occupies a significant place in the newly formed Kurdistan region of Iraq. English is considered a window of opportunities and economic development of its people and the region. The quality of teaching and learning plays a crucial role in achieving the objective. However, the lack of trained teachers in English at the school level has severely affected the standards of English at the tertiary level. Students pursuing undergraduate courses at Cihan University find it a challenging task to meet the required standards. The lack of a strong foundation in English in addition to the constraints of time and the high standards of the curriculum at the tertiary level makes it more challenging for the teachers to teach them writing skills. The present study aims at exposing the Kurdish students to English collocations vocabulary through Mobile Assisted Language Learning (MALL) to enhance their writing and communicative purposes. Twenty-five students from undergraduate courses were randomly selected for the purpose of the study. The results have shown an improved performance of the students in using the right collocations. The study brings out the need for integrating MALL in the regular curriculum at the tertiary levels in Kurdistan.
\end{abstract}

Keywords - Collocations, Writing, Mobile Assisted Language Learning

\section{$1 \quad$ Introduction}

English is a foreign language for the Kurdish who are predominately an Indo-European ethnolinguistic group in Iraq. However, over the years, they share more affinity with the English language than Arabic [1]. Since gaining autonomy in 1991, the Kurdistan Region of Iraq has taken significant steps to reform, revamp and rejuvenate education in the region by setting up several universities, colleges, and schools, passing new education legislations. However, the serious shortage of well-trained teachers of English, dearth of English teacher training, and lack of proper infrastructure continue to cripple quality English language instruction in the region as cited in [1]. Furthermore, the paucity of academic and professional publications in the Kurdish language raise the demand for English to Kurdish people. Learning English has increasingly been viewed as a panacea for success in academia, job market for many Kurdish learners. 
Firth's quote sums up what a collocation essentially is when he says, "You shall know a word by the company it keeps" [2]. A collocation is a pair or group of words that are often used together and how the words go together. These combinations sound natural to native speakers, but ESL/EFL students have to make a special effort to learn them, as they are often difficult to guess. Teaching and learning collocations gain significance for enhancing speaking and writing skills of the tertiary level students. Research studies showed that collocations not only play a pivotal role in language production and comprehension but also act as a key indicator of L2 learners' overall proficiency in the field of second language acquisition. Furthermore, Linguistic investigations into collocations have provided extensive evidence that native-speaker texts are on the most part formulaic and contain extensive use of collocations [3] [4] [5][6].

The widespread digital technologies have changed the landscape of second language teaching and learning around the world. Mobile technologies have brought a vast change in how people communicate access information and learn. The multi-modal communication features of Smartphones with powerful processors offer multiple affordances for language learning. The ubiquity of mobile devices and the rapid spread of connectivity even in developing countries make mobile technologies a viable option for delivering quality education as stated in the UNESCO policy document in mobile learning [7]. According to the UNESCO (2012) report, it is for the first time in history that a majority of people can afford to buy a personal ICT device and that is in the form of mobile phones [8]. The study attempts to present how Kurdish tertiary students responded to mobile learning experience for enhancing their English language skills, especially their awareness and use of collocations.

\subsection{Context of the study}

The students in the Middle East in general and the students at Cihan University, in particular, are found reluctant to bring basic learning tools like books and pens to the classroom. They show little interest in learning in conventional methods and they prefer to capture everything in their smartphones rather than taking it down in the notebook. This heavy reliance on technology offers both challenges and opportunities for the language teacher. The opportunity lies in exploiting the present learning habits of the learners and designing tasks, which can be done on the smartphones that can engage their attention and motivate them. In this scenario, the researcher has opted for mobile learning to catch the imagination of the students and to engage, motivate them towards learning English. As learners tend to rely heavily on social media, the researcher has attempted to share learning resources and learning tasks using the same social media platform.

\section{$2 \quad$ Literature Review}

For a student who is learning English as a foreign language may not have enough exposure to English to identify the oddity in the expressions- 'quick cars' and 'quick food'. Unless the learner is trained in the use of collocations, he will not be in a position 
to distinguish between what sounds natural in English what sounds unnatural or peculiar. In many definitions of collocation, the "co-occurrence" of words introduces the core concept of collocations. Therefore, a typical definition of collocation is "words which are statistically much more likely to appear together than random chance suggests" [9].

Acquiring a second language involves integrating the four main skills including listening, speaking, reading, and writing, which leads to effective communication. One pivotal factor in this process is the amount of vocabulary one possesses as vocabulary forms the biggest part of the meaning of any language [10]. As a result, vocabulary acquisition is now receiving significant attention in second language pedagogy and research. Furthermore, how learners acquire vocabulary effectively and efficiently and how it can best be taught are debatable issues in applied linguistics [11].

Among the preferred techniques, research shows that teaching words in chunks can greatly enhance the range of the words one can apply in the negotiation of meaning as stated in [12]. The lexical approach to language teaching gives more emphasis on presenting the words in language chunks but not in isolation [13]. In this framework, a distinction can be made between vocabulary and lexicon, whereas the former concerns words in isolation and the latter is related to words along with their surrounding context or collocations [14].

Learning collocations using smartphones provides a distinct advantage to the learners. They can easily find a good number of examples with a simple Google search on their mobile devices. Moreover, there is an app called dictionary of collocations published by Oxford University Press which is readily available for easy reference.

Smartphones offer many affordances for language learning collaboratively. The affordances offered by smartphones can be exploited to engage the learner beyond the classroom. Moreover, device ownership makes a lot of difference in how learners use the device, and BYOD (Bring Your Own Device) helps personalizing their learning [15].

\section{Purpose of the Study}

Though $98 \%$ of the Kurdish students carry smartphones or i-Pads to the classroom, there has been no research on how smart mobile devices could be integrated with teaching and learning methods. The present study undertakes how the students perceive the use of the latest technological tools for improving their foreign language skills. The present study aims at studying the following research questions:

1. How do Kurdish tertiary learners respond to mobile learning?

2. How do the learners respond to the collocation contests on the social media platform WhatsApp?

3. What is the impact of mobile learning on improving their awareness of collocations? 


\section{$4 \quad$ Methodology}

Methodology: The study has adopted a mixed-methods approach with Bring Your Own Device (BYOD) model.

Participants: The quasi-experimental study was undertaken with the second-year students of the Department of Translation, Cihan University.

Procedure: An exclusive WhatsApp group was created and all the interested secondyear students of the Department of Translation $(\mathrm{n}=25)$ were added to the group. The duration of the training was for three weeks and every alternate day a set of collocations was posted on the WhatsApp group and the participants were asked to frame as many grammatically correct sentences as possible using the given collocation sets (verb + noun). The study included a feature of competition to motivate them further. The participants who posted more number of grammatically correct sentences using the given sets of collocations during the week were adjudged as the winners of the week.

Data Collection: The number of sentences posted in the group was collected and the same was divided into correct and incorrect sentences. Besides, the scores of pre-test and post-test were taken for assessing the improvement.

Data Analysis: Paired Sample t-test was conducted to assess if there is any significant difference in the performance of the students in using the collocations.

\section{$5 \quad$ Results}

The results of the study are presented in the order of the research questions:

1. How do Kurdish tertiary learners respond to mobile learning?

The one-on-one interviews conducted during and after the study revealed that the participants were motivated to learn the language in an engaging way using the technology. They preferred task-based learning and the competition motivated them to participate actively. Twenty-five students out of thirty have come forward to participate in the study.

2. How do the learners respond to the collocation contests on the social media platform WhatsApp?

As WhatsApp is the regular mode of communication for most of the participants, it enabled them to communicate with one another and with the teacher anytime and from anywhere. The participants posted their doubts in the WhatsApp group created exclusively for this purpose. 


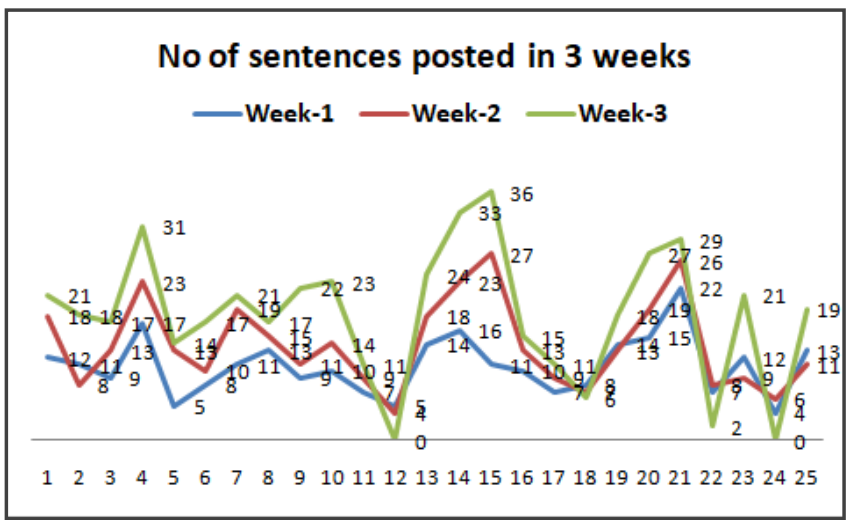

Fig. 1. The number of sentences posted in three weeks

Further, the number of sentences the participants posted grew gradually in number. Twenty-two out of twenty-five participants, who participated in the study, were actively involved in the study. Figure 1 indicates the number of correct sentences posted by each of the participant during the study that spread for three weeks.

3. 3. What is the impact of mobile learning on improving their awareness of collocations?

Figure 2 presents the scores obtained by all the twenty-five participants both in the pre-test and post-test. It can be observed from the same that there was a marked improvement in the scores of the participants.

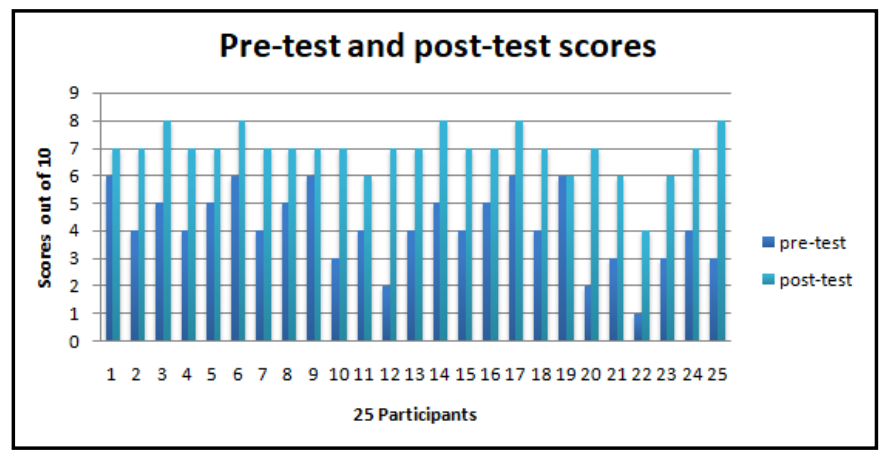

Fig. 2. Pre-test and post-test scores

From the personal interviews with the participants, it was noted that sharing sentences through WhatsApp has engaged them well. The competitive nature behind posting the sentences on the given sets of collocations motivated them to compose sentences on their own. The participants shared they learned many things from the feedback given by the teacher in the group on the correctness of sentences. Moreover, sharing sentences on the group also led to a collaborative learning experience. 
Moreover, descriptive statistical analysis was also performed to find if there is any statistically significant difference in the performance of the students after being exposed to MALL.

Table 1. Descriptive Statistical Analysis

\begin{tabular}{|l|c|c|c|}
\hline & Sample size & mean & s.d \\
\hline Experimental Group & $\mathrm{n}_{\mathrm{a}}=25$ & $\mathrm{x}_{\mathrm{a}}=6.92$ & $\mathrm{~S}_{\mathrm{a}}=0.8622$ \\
\hline Controlled Group & $\mathrm{n}_{\mathrm{b}}=25$ & $\mathrm{x}_{\mathrm{b}}=4.72$ & $\mathrm{~S}_{\mathrm{b}}=0.9798$ \\
\hline
\end{tabular}

- Null Hypothesis: $\mathrm{H} 0: \mu \mathrm{A}-\mu \mathrm{B}(=\delta)=0$ (i.e., The performance in the pretest and the post-test is same for both in Experimental group and controlled group treatment)

- Alternative Hypothesis: $\mathrm{H} 1: \mu \mathrm{A}-\mu \mathrm{B}>0$ (i.e., The performance of the students in Experimental group is better than the performance of controlled group treatment)

- L.O.S: $\alpha=0.05$ (Right oriented Tailed Test) t0.005=1.761 with dof

$$
v=\mathrm{n} 1+\mathrm{n} 2-2=48
$$

- Critical Region: $|\mathrm{tcal}|>|\mathrm{t} \alpha / 2|$ (reject Null Hypothesis)

- Computation: t_cal = 8.42

- Decision: Reject Null Hypothesis since $\mid$ tcal $|>| t \alpha / 2$

i.e., the performance of the students in Experimental group is better than the performance of students in controlled group treatment as shown in table 1.

\section{Discussion}

The study revealed the engaging feature of mobile technologies. In a study [16] it was indicated that university students consume nearly more than eight hours on their smartphones. It was also suggested that this addiction can be effectively and purposefully used for the development of student learning performance in different fields of the study [17]. The ubiquity of the mobile devices possibly supports students' access to learning materials anytime and anywhere leading to an increase in contact with both formal and informal learning as stated in [18].

Another study stated that mobile learning (M-learning) is being used extensively in teaching and learning foreign languages, which further widens the mobility of learners [19]. Teachers had a great opportunity to change their teaching methods to take full advantage of the features of mobile technologies to create innovative learning approaches aligned with the needs of the e-generation [20].

The participants who are reluctant to take down notes in the classroom with a pen and a book were observed noticing and reading every comment posted in the WhatsApp group. The comments they shared on the group on the sentences made by others and the mutual encouragement and support they extended to the best performing participants were proof enough to say that teaching through social media platforms like WhatsApp can be more engaging to the learners. They were involved actively during the entire period of the study. Out of twenty-five participants, twenty-two participants were very active. The three participants who were not so active were interviewed by 
the researcher to obtain the reasons for their low levels of interaction. They cited problems that were personal in nature but not related to either the language tasks or social media. They expressed a keen desire to participate in the next online training program using mobile phones. As MALL offers immense scope for teaching and learning for both teachers and learners, it is high time mobile learning is integrated with the regular curriculum.

Further, the study [21] reveals that students have a positive attitude towards using online tools in ESL writing. It is suggested that teachers should support and encourage students to put in use online tools to enhance and enrich their writing skills.

The social media platform WhatsApp is found to be a productive tool to engage students in productive academic discussions even beyond the classroom. Furthermore, it provides ample room for teachers and learners to interact outside the classroom. [22].

\section{Conclusion}

The study revealed that the participants were motivated to learn the language in an engaging way using mobile technologies. Interaction on WhatsApp has led to greater exposure to language outside the classroom and participants have interacted using a good number of collocations collected from different sources leading to a rich collaborative learning experience. It has reflected in the improved performance in their writing tasks.

\section{References}

[1] Sofi-Karim Mahdi (2015) English Language Teaching in the Kurdistan Region of Iraq

[2] Firth, J. R. 1957. “A synopsis of linguistic theory 1930-1955”. In F. Palmer (Ed.), Selected Papers of J. R. Firth 1952-1959. London: Longman, 168-205.

[3] Altenberg, B. (1998). On the phraseology of spoken English: The evidence of recurrent word-combinations. In A. P. Cowie (Ed.), Phraseology: Theory, analysis, and applications (pp. 101-122). Oxford: Oxford University Press.

[4] Biber, D., Johansson, S., Leech, G., et al. (1999). Longman grammar of spoken and written English. Harlow: Longman. https://doi.org/10.1017/s0022226702211627

[5] Cowie, A. P. (1991). Multiword Units in Newspaper Language. In S. Granger (Ed.), Perspectiveson the English lexicon: A tribute to Jacques Van Roey (pp. 101-116). Louvain-laNeuve:Cahiers de I'Institut de Linguistique de Louvain. https://doi.org/10.2143/cill.17.1. 2016699

[6] Howarth, P. (1998). The phraseology of learners' academic writing. A. P. Cowie (Ed.), Phraseology: Theory, analysis, and applications (pp. 161-186). Oxford: Oxford UniversityPress.

[7] West, M., \&Vosloo, S. (2013). Policy Guidelines for Mobile Learning. Retrieved from http://www.unesco.org

[8] UNESCO. (2012). Mobile learning and policies: key issues to consider. UNESCO. http://unesdoc.unesco.org/images/0021/002176/217638E.pdf

[9] Lewis, M. (2001) there is nothing as practical as a good theory Teaching Collocation. Hove, England: Language Teaching Publication.

[10] McCarthy, M. (1988). Vocabulary. Oxford: Oxford University Press.

[11] Brown, D. F. (1947) Advanced vocabulary teaching: the problem of collocation. RELC Journal, $5,1011$. 
[12] Nattinger, J.R., and J.S. DeCarrico. (1992). Lexical phrases and language teaching. Oxford: Oxford University Press. https://doi.org/10.7202/001902ar

[13] Willis, D \& J. Willis. (2006). Doing Task-based Teaching. Oxford: Hill, J., and Michael Lewis (1999) Dictionary of Selected Collocations, Hove, England: Language Teaching Publication.

[14] Lewis, M (2006).Teaching Collocation. Further Development in Lexical Approach. Hove: Language Teaching Publications.

[15] Kukulska-Hulme, A. (2009). Will mobile learning change language learning? ReCALL: Journal of Eurocall, 21(2), 157-165. https://doi.org/10.1017/s0958344009000202

[16] Lewis, M.(2000) Teaching Collocation: Further Developments in the Lexical Approach. Hampshire: Heinle Cengage Learning.

[17] Alkhunzain, A. S. (2019). An Empirical Study on Smartphone Addiction of the University Students. International Journal of Interactive Mobile Technologies (IJIM), 13(12), 184. https://doi.org/10.3991/ijim.v13i12.11120

[18] Eppard, J., Hojeij, Z., Ozdemir-Ayber, P., Rodjan-Helder, M., \&Baroudi, S. (2019). Using mobile learning tools in higher education: A UAE Case. International Journal of Interactive Mobile Technologies, 13(11), 51-69. https://doi.org/10.3991/ijim.v13i11.10823

[19] Khan, R. M. I., Radzuan, N. R. M., Alkhunaizan, A. S., Mustafa, G., \& Khan, I. (2019). The efficacy of MALL instruction in business English learning. International Journal of Interactive Mobile Technologies, 13(8), 60-73. https://doi.org/10.3991/ijim.v13i08.9562

[20] Shraim, K. (2014). A case study of mobile technology-enabled English language learning: The Amazon Kindle e-reader initiative in Palestine. International Journal of Interactive Mobile Technologies, 8(3), 25-31. https://doi.org/10.3991/ijim.v8i3.3770

[21] Grami, G. (2020). An Evaluation of Online and Automated English Writing Assistants: Collocations and Idioms Checkers. International Journal Of Emerging Technologies In Learning (IJET), 15(04), pp. 218-226. https://doi.org/10.3991/ijet.v15i04.11782

[22] Akkara, S., Anumula, V., \& Mallampalli, M. (2020). Impact of WhatsApp Interaction on Improving L2 Speaking Skills. International Journal Of Emerging Technologies In Learning (IJET), 15(03), pp. 250-259. https://doi.org/10.3991/ijet.v15i03.11534

\section{Authors}

Sasi Sekhar Mallampalli is pursuing research in English Language Teaching (ELT) at Uttaranchal University, Dehradun, India. He is currently working at Cihan University, Erbil, Kurdistan Iraq. He has participated and presented papers at national and international conferences. His research interests include Writing Skills at secondary and tertiary levels, Mobile Assisted Language Learning, Teaching with Technologies.

mallampallisasisekhar@gmail.com

Dr. Shriya Goyal has more than 18 years of experience in teaching at Postgraduate and Undergraduate level along with research experience. Many Research Scholars are pursuing their Ph.D. Research Work under her supervision. She has presented Research Papers and attended National and International Conferences, Seminars \& Workshops, and has many published articles in International Journals to her credit.

dr_shriya19@yahoo.com

Article submitted 2020-07-04. Resubmitted 2020-08-12. Final acceptance 2020-08-15. Final version published as submitted by the authors. 